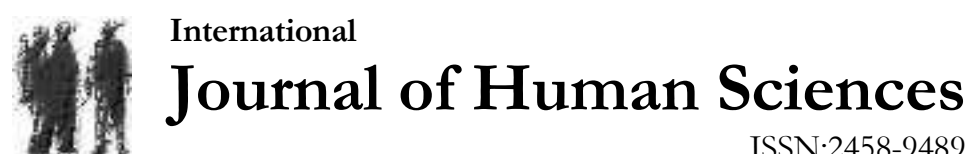

Volume: 18 Issue: 4 Year: 2021

\section{The perceptions of university students' professional socialization process}

\author{
Hatice Öner ${ }^{1}$ \\ Yildiz Denat ${ }^{2}$ \\ Nermin Koruklu ${ }^{3}$
}

\begin{abstract}
The purpose of this study is to determine the perceptions of university student's professional socialization process. The study adopted the qualitative research design. Easily accessible case sampling method, was used to determine the participants of the study group. The study group consisted of 16 students. The data were collected through two focus groups. The data of the study were analysed using the content analysis method. According to the findings of the content analysis the themes "adaptation to society", "professional role achievements", and "adoption of the profession", and relevant sub-themes were identified. The results of the study revealed that students who were studying at both faculties expressed the concept of 'professional socialization' in a multidimensional way. In the light of the findings obtained from the research, it is proposed to make new curriculum arrangements that will provide the development of professional socialization for students.
\end{abstract}

Keywords: Perception of professional socialization, Professional identity, University students, Focus group, Qualitative study.

\section{Introduction}

Professional socialization is a complex process of internalizing professional norms and acquiring professional knowledge, skills, and identity (Corrêa Junıor, Souza Neto \& Vedovatto Iza, 2017; Ke, Kuo \& Chich-Hsiu, 2017; Sadeghi Avval Shahr, Yazdani, \& Afshar, 2019). In the literature, professional socialization is defined both as a process and an outcome. As a process, professional socialization is the construction of professional values, norms and perspectives. The common point of the existed definitions is the presence of self-opinion, knowledge, and responsibilities as a member of a professional body (Thrasher et al., 2015; Tahmasbi et al., 2017). Cohen (1981) indicated that and individual internalizes the values and norms of the profession within the professional socialization process, and the concept of identity is reshaped with these new values.

\footnotetext{
${ }^{1}$ Assist. Prof. Dr., Aydin Adnan Menderes University, Faculty of Nursing, Department of Mental Health and Diseases Nursing, honer@adu.edu.tr, ht oner@hotmail.com (iD) Orcid ID: 0000-0002-6556-5753

2 Assoc. Prof. Dr., Aydin Adnan Menderes University, Faculty of Nursing, Department of Fundamentals Nursing, denat09@gmail.com (iD) Orcid ID: 0000-0001-9633-8951

${ }^{3}$ Prof. Dr., Aydın Adnan Menderes University, Faculty of Education, Department of Educational Sciences, Psychological Counseling and Guidance in Education, nonerkoruklu@gmail.com (iD) Orcid ID: 0000-0003-1577-8352
} 
Öner, H., Denat, Y., \& Koruklu, N. (2021). The perceptions of university students' professional socialization process. Journal of Human Sciences, 18(4), 550-563. doi:10.14687/jhs.v18i4.6170

Professional socialization points out to the intended and unintended outcomes of a study program (Merton 1969). In this process, certain educational experiences that are gained through socialization might be supportive or unsupportive for future professional development (Strouse et al., 2016; Jong et al., 2017; Salisu et al., 2019). While factors such as supportive learning environment, positive experiences, clarity of the role expectations, comprehensive orientation process and self-confidence make a positive contribution to the professional identity development (Jong et al., 2017; Salisu et al., 2019), the presence of an inappropriate role model in the working environment, a negative learning environment, experiencing conflicts with other professionals, oppressive and grade-oriented approach of the instructor, different and irregular implementation fields obstructs the process (Tahmasbi et al., 2017; Salisu et al., 2019).

Professional socialization occurs through acquiring the values, attitudes, skills, and knowledge of a particular group, in other words, the culture of the group, in a selective manner (Thrasher et al., 2015; Strouse, and Nickerson, 2016; Dinmohammadi, Peyrovi, \& Mehrdad, 2017). Professional socialization starts to occur with the process of education and may continue after the graduation of the student (Lum, 1988; Thrasher et al., 2015; Romar and Frisk, 2017).

Merton (1957) emphasized that the professional socialization process commences before students enrolled in the training programme and defined this process as 'anticipatory socialization' (as cited in Ousey, 2009). In this phase, a child try out future professional roles through the images and impressions that emerge in games (Lum, 1988). At this point, education and training were particularly emphasized as the main indicators of socialization (Lruie, 1981). Another definition made by Light (1979) stated that professional socialization is an interactive process, yet there are uncertainties about it. According to Light, the society is determinative and directional on the professional behaviours of an individual who is in the process of receiving professional education. Therefore, Light suggested to evaluate the data collected by educators within the education process from an objective perspective, to eliminate these uncertainties (Light, 1979). Shuval and Adler (1980) stressed that the modelling process is multidimensional in the professional socialization process, and there is no single dominant factor. The writers highlighted that the process does not depend only on the qualities of the models or characteristics of the situation, but it also depends on the nature of different norms and values (Shuval and Adler, 1980). Shuval (1980) examined the socialization process at three levels: "pre-socialization, formal socialization, and post-socialization". Davis (1975) noted that and this process which begins with the inexperienced period, continues with the internalization of values and norms and ends with the period that values and norms are internalized, and the individual experiences professionalism (cited in Ousey, 2009). These stages were: initial innocence, psyching out, role simulation, provisional internalization and stable internalization.

Many theorists suggested perspectives and models on the socialization and professional socialization process. Cohen (1981) is among the researchers who made important contributions to the field. The model developed by Cohen (1981) explained how the student experienced a professional role at each level and how the student felt in this process. According to the model the levels of professional socialization were defined as "unilateral dependence, negative/ independence, dependence/ mutuality, and interdependence". In this process, the student is affected by the external controls and is likely to accept concepts without questioning (Cohen, 1981) and begins to question the concepts in time (Cohen, 1981). In the following phases of the process, the feelings of empathy and commitment begin to develop, and the student begins to relate previous knowledge with new material. As a result of the educational process, the student begins to take independent decisions and develops an autonomy. At this stage, the student becomes a professional. Reaching to this phase has a critical importance for all professionals (Yazdannik, Yousefy \& Mohammad, 2017). In the phases of development, the socialization process of the individual is affected by his/her previous learning and experiences (Ke et al., 2017), relationships and interactions (Cerit and Temelli, 2018), attitudes and values of the family, intellectual level and level of motivation at the beginning of the educational training (Neto, Iza \& Silva, 2017). The 
Öner, H., Denat, Y., \& Koruklu, N. (2021). The perceptions of university students' professional socialization process. Journal of Human Sciences, 18(4), 550-563. doi:10.14687/jhs.v18i4.6170

positive continuation of this process helps to enhance the awareness, strengths, competencies, and the critical skills of the individual (MacArthur, Dailey \& Villagran, 2016;Langrehr, Green \& Lantz, 2017; Neto et al., 2017). The ultimate objective of the professional socialisation process is to enable the individual to identify himself/herself with the profession and develop a professional identity by internalizing knowledge, skills, norms, and values of the profession (Freund et al., 2017; McGregor and Nova Scotia, 2019). Effective and competent cooperation between educators and students and guidance has key importance for achieving these objectives and outcomes (Mac Arthur et al., 2016; Langrehr et al., 2017; Salisu et al., 2019).

In order for professional identity development to be at the desired level, students must internalize this process. However, students may experience problems in different areas when they start their undergraduate education. It has been stated that the quality of the emotions experienced by the teacher candidates during their professional practice training affects their professional identity development. It has been stated that the future professional role development of teacher candidates who have negative experiences may be adversely affected (Sancak Aydın \& Çilsalar Sağnak, 2020). Similarly, nursing students stated that their perceptions of the profession were negatively affected when they could not communicate with patients, other health professionals and nurses during clinical experiences (Dinmohammadi vd., 2017; Zarshenas et al., 2014). All these problems experienced in the vocational education process can reduce the motivation of the students and cause the professional identity development to be interrupted.

To date, the majority of the studies has focused on the field of health and nursing (Limoges and Jagos, 2015; Strouse et al., 2016; Dinmohammadi et al., 2017), yet other fields of professional education have not been extensively studied and there are only a few studies in the literature (Mazerolle et al., 2015; Thrasher et al. 2015; Balci et al., 2019). Most studies in the literature have focused on the conceptual analysis of professional socialization, sociological analysis of professional socialization, and its impact, the process of professional socialization and related experiences, the development of professional socialization, and issues of professional identity (Perez, 2016; Tahmasbi et al., 2017; Sadeghi Avval Shahr et al., 2019). However, previous studies have not dealt with evaluating students' perceptions of professional socialization. Nevertheless, revealing the distinctions between perceptions of university students who are trained to be a part of different professional groups and between the educational processes, increasing students' awareness on the issue, and evaluating the contribution of university education to this process have great importance to make regulations in educational planning processes.

The primary aim of this study is to identify the perceptions of students' who were studying at different study programs of different departments on the process of professional socialization.This research study seeks to understand what are the perceptions of students, who are studying at different departments, on the process of professional socialization?

\section{Methods}

\section{Participants and Design}

The study adopted the qualitative research design and phenomenological approach. Phenomenology is not only a philosophical approach, but it is also a research method that uses certain methods to assist the individual to comprehend his or her perception of life, interests, and experiences (Hesse-Biber and Leavy, 2006). The participants of a phenomenological study are expected to "have lived experiences related to the research phenomenon and express these lived experiences explicitly" (Creswell, 2016). Focus group interviews are among the data collection tools used in phenomenological studies.

The study group included 6 students studying at the faculty of education, and 10 students studying at the faculty of nursing. The study group consisted of 16 students in total. Easily accessible case sampling method, which is one of the purposeful sampling methods was used to determine the participants of the study group. The data were collected through two focus group 
Öner, H., Denat, Y., \& Koruklu, N. (2021). The perceptions of university students' professional socialization process. Journal of Human Sciences, 18(4), 550-563. doi:10.14687/jhs.v18i4.6170

meetings. The data of the study were analysed using the content analysis method. In easily accessible situation sampling, the researcher chooses a situation that is close and easy to access. This method adds speed and practicality to research (Yildırım and Simsek, 2008). The participation of the students occurred on a voluntary basis, and the study group was formed based on the criteria of the (i.e. department, gender, age, grade, etc.). As a result, two focused groups were created. The first focused group included 10 students studying at the faculty of nursing, and the second focused group included 6 students studying at the faculty of education. The study was carried out between 24 May and 22 July 2019. Given that a large number of participants in a group may diminish the dynamism of the group, decrease the interaction among the participants, and complicate the control of the group, the number of students in a focused group was limited to 10 students (Edmunds, 2000).

The participants of the study group included 9 females (\%56.25) and 7 males (\%43.75). The age average of the participants was found as 21.37. The study participants included 10 students who were studying at the faculty of nursing and 6 students who were studying at the faculty of education.

\section{Data Collection Tools}

Data for this study were collected using a "personal information form" on sociodemographic characteristics of the participants and "focused group interviews".

\section{Personal information form}

The form included questions on participants' department, grade, age, gender, etc.

\section{Focused group interview}

The data were collected using semi-structured and non-guiding focus group method. Focus group interview is an interview-discussion method conducted with a group on a subject that is defined in the context of qualitative research design and methods (Yildirim and Simsek, 2008). Focus group interview is a systematic data collection tool used in qualitative research. Focus group interviews lasted around 50 minutes and 1 hour 15 minutes. In the introduction phase the researchers introduced themselves, explained the purpose of the research to the participants, and the focus group interview was started after the participants introduced themselves. The interviews questions were appropriate to the level of the participants, clear, and were type of questions that could be ask in a causal chat.

In line with the purpose of the research, semi-structured open-ended questions were asked to the students. These questions were as follows:

1. What is the process of professional socialization?

2. What technical competences, professional values and attitudes should individuals with professional socialization have?

3. What is a professional culture? What the concept of professional culture covers?

4. What should be the components of a professional role?

\section{Data Collection}

In the initial phase of the interview process, meetings were conducted with each student before the focus group interviews took place, and a meeting time that was suitable for both parties was determined. Afterwards, participants and researchers gathered in a room that was convenient to have a face to face communication. At the beginning of each group study, the purpose of the study was explained to the participants and the written consent of the students was received. After students gave their consent, personal information forms were given to students to obtain 
information on their socio-demographic characteristics. The interview begun after the students had been informed that the discussion was going to be recorded via a voice recorder. Based on the semi-structured interview method, the students were encouraged to express their opinions on the research questions, and an effort was put to include each student's opinions on the questions. In this way, group dynamism was established. Following the interview session, the voice recordings were transcribed.

\section{Data Analysis}

The data of the study were analysed using the content analysis method. Content analysis is a systematic method that allows summarizing a text through smaller content categories using codes based on certain rules (Buyukozturk et al., 2014). In this context, first of all, the focus group meetings that were recorded by a voice recorder were transcribed. Afterwards, the experts coded the answers given to each question separately. Based on these codes, the themes and sub-themes were created.

\section{$V$ alidity and reliability}

The personal information form and the question form were examined by a faculty member, who had experience in teaching and conducting qualitative research, to ensure the internal validity of the study, and the form was finalized according to the feedback of the faculty member. According to Yildırim and Simsek (2008), a researcher who conducts qualitative research should provide a detailed explanation of each phase of the research to ensure the external validity and generalize the results to similar environments. In this context, detailed explanations of the research phases and results were provided to ensure the external validity of the study.

To enhance the reliability of the data coding process of the study, the data were coded by the researcher, the focus group interviews were coded independently by another faculty member who was trained and experienced in qualitative research, and the results were compared.

To calculate the reliability of the research study, the reliability formula suggested by Miles and Huberman (1994) was used.

Consensus Percentage $=$ Consensus $/($ Consensus + Disagreement $) \times 100$

According to the given formula, the researchers reached a consensus and the percentage was found as $111 /(111+15) \times 100=88 \%$ The consensus percentage was calculated using the codes. A reliability calculation value over $\% 80$ is accepted as a reliable value for a research study (Miles and Huberman, 1994; Buyukozturk, et al., 2008). As a result, the values were accepted as reliable for the study.

\section{Ethical considerations}

The ethics committee approval of the study (Protocol No: 2019/081) was received from the Aydın Adnan Menderes University Faculty of Nursing Non-Invasive Clinical Research Ethics Committee. Furthermore, institutional approvals were received form the Dean's Office of the Faculty of Nursing and Faculty of Education to conduct the research study. Prior to the research, the purpose of the study and expected contributions of the study to the educational processes and development of professional identity were explained, and verbal informed consent of the students who accepted to participate to the study were received. 
Öner, H., Denat, Y., \& Koruklu, N. (2021). The perceptions of university students' professional socialization process. Journal of Human Sciences, 18(4), 550-563. doi:10.14687/jhs.v18i4.6170

\section{Results}

The themes and sub-themes obtained from the analysis of the focus group interviews are shown in Table 1.

Table 1: Perceptions of students on the process of professional socialization

\begin{tabular}{|c|c|c|}
\hline Theme & Sub-Themes & Codes \\
\hline $\begin{array}{l}\text { Adaptation to } \\
\text { society }\end{array}$ & Social service/benevolence & $\begin{array}{ll}- & \text { Meeting the expectations of society } \\
- & \text { Showing respect to rights and privacy } \\
- & \text { Socializing }\end{array}$ \\
\hline \multirow[t]{3}{*}{$\begin{array}{l}\text { Professional role } \\
\text { achievement }\end{array}$} & Technical achievements & $\begin{array}{ll}- & \text { Communication skills } \\
- & \text { Organization } \\
- & \text { Observation } \\
- & \text { Being competent } \\
- & \text { Fulfilling the role } \\
- & \text { Standard applications }\end{array}$ \\
\hline & Emotional achievements & $\begin{array}{ll}- & \text { Motivation } \\
\text { - } & \text { Emotional Awareness } \\
\text { - } & \text { Control of Emotions } \\
\text { - } & \text { Ability to be a teamPsychological resilience } \\
\text { - } & \text { Sense of belonging } \\
\text { - } & \text { Affection } \\
\text { - } & \text { Job Satisfaction } \\
\end{array}$ \\
\hline & Cognitive achievements & $\begin{array}{ll}- & \text { Problem-solving } \\
- & \text { Knowing rights } \\
- & \text { Being open/ ready to innovation } \\
- & \text { Being focused } \\
- & \text { Respecting limits } \\
- & \text { Sense of Responsibility } \\
- & \text { Following recent scientific knowledge } \\
- & \text { Being investigative } \\
- & \text { Having sufficient professional knowledge }\end{array}$ \\
\hline \multirow[t]{2}{*}{$\begin{array}{l}\text { Adoption of the } \\
\text { profession }\end{array}$} & Professional identity & $\begin{array}{ll}- & \text { Self-respect } \\
- & \text { Being bonest } \\
- & \text { Being generous } \\
- & \text { Being proponent } \\
- & \text { Being objective } \\
- & \text { Being flexible } \\
- & \text { Being well-adjusted } \\
- & \text { Being virtuous } \\
- & \text { Being patient } \\
- & \text { Being trustworthy } \\
- & \text { Being consistent } \\
- & \text { Being determinant } \\
- & \text { Being cheerful } \\
- & \text { Being respectful } \\
- & \text { Being responsible } \\
- & \text { Being open to innovation }\end{array}$ \\
\hline & Professional Culture & $\begin{array}{l}\text { - } \quad \text { Every aspect of the profession (behaviour, style, language, } \\
\text { standpoint, and way of thinking) } \\
\text { - } \quad \text { Consistency between the personality and profession } \\
\text { - } \quad \text { Learning about other cultures } \\
\text { - } \quad \text { The occurrence of professional identity through implementation } \\
\text { - } \quad \text { An obstacle for change } \\
\text { - } \quad \text { Acceptance of differences } \\
\text { - } \quad \text { Common language } \\
\text { - } \quad \text { Integration to the society } \\
\text { - } \quad \text { Competencies pertain to the culture } \\
\text { - } \quad \text { Having ethical principles }\end{array}$ \\
\hline
\end{tabular}


Öner, H., Denat, Y., \& Koruklu, N. (2021). The perceptions of university students' professional socialization process. Journal of Human Sciences, 18(4), 550-563. doi:10.14687/jhs.v18i4.6170

This section presents the themes, sub-themes and relevant codes along with the students' expressions.

\section{Theme 1: Social adaptation}

The theme was created based on the definition of professional socialization made by the students and the answers given by the students to the related questions. The students highlighted that professional socialization is indeed a process of social adaptation. Accordingly, the sub-theme social service/ benevolence was identified. The codes related to the theme and the sub-theme were identified as "fulfilling the expectations of the society, showing respect to rights and privacy, and socialization". Regarding the understanding of professional socialization, the students said that;

We get professional with the lessons we take and also and get involved in a community. (S11).

It is a process in which the individual fulfils her/ his roles and adapts to society. (S3).

Making anything professionally. Realizing social roles not in a way that we used to, but more scientifically and professionally", and S6 expressed that "I think it is the best possible way that socializing process can occur. I perceive professionalism as an adaptation to the environment in the best possible way considering the persons and personal characteristics (S2).

\section{Theme 2: Professional role achievement}

In the context of the theme, three sub-themes technical achievements, emotional achievements, and cognitive achievements were identified. The codes that were related to the sub-theme 'technical achievements' included "communication skills, organization, observation, being competent, fulfilling the role, and standard applications". The codes related to the sub-theme 'emotional achievements' included "motivation, emotional awareness, control of emotions, "ability to be a team", psychological resilience, sense of belonging, affection, job satisfaction". And lastly, the cognitive achievements related to the sub-theme 'cognitive achievements' included "problemsolving, knowing rights, being open/ready to innovation, being focused, respecting limits, sense of responsibility, following recent scientific knowledge, being investigative, and having sufficient professional knowledge". The themes and sub-themes were identified in the context of the question: What technical competences, professional values and attitudes should individuals with professional socialization have?

The codes related to the sub-theme 'technical achievements' were identified as "communication skills, organization, observation, being competent and standards applications" were identified. Regarding these codes, the students stressed the importance of effective communication in terms of being a member of a professional occupation. The students said that;

For example, I am studying in the department of mathematics education. Even now, I think that I should observe students when I interact with them. A good observation is important for self-guidance. (S6).

In general, communication skills are... They are a part of every profession... To listen, to understand... These skills should be gained. (S5).

Gaining experience requires to put an effort for organization. (S8).

There should be an eye-contact, effective communication is very important. The individual should feel important. (S10).

The codes related to the sub-theme 'emotional achievements' were identified as "motivation, emotional awareness, control of emotions, psychological resilience, affection, and job satisfaction". Regarding the code 'job satisfaction', the students said that;

An individual should feel that he/she belongs to the job and the environment... And, should feel satisfied with what he/she does. (S1).

The control of emotions is very important. Even there is something unpleasant going on, when a teacher wears his uniform he/she should be able to leave other things behind. (S10).

I am a psychological counsellor, I think psychological resilience is the most important trait... (S6).

The codes related to the sub-theme 'cognitive achievements' were identified as "solving problems, knowing rights, being open/ready to innovation, being focused, respecting limits, sense 
Öner, H., Denat, Y., \& Koruklu, N. (2021). The perceptions of university students' professional socialization process. Journal of Human Sciences, 18(4), 550-563. doi:10.14687/jhs.v18i4.6170

of responsibility, following recent scientific knowledge, being investigative and having sufficient professional knowledge". The students said that;

Ourprofession is open to change, and the knowledge is not constant. There is a need to renew the knowledge, develop a different perspective on issues, and strengthen the technique. (S10).

Professional knowledge must be sufficient. I need to receive an accurate answer to my question to meet my expectations. (S6).

I think self-renewal is necessary. Related to the field... A teacher should read constantly (S3).

It is a responsibility of personal relationships. Because it means professional standpoint. In the most basic sense, it is about fulfilling the demands and expectations. (S10).

\section{Theme 3: Adoption of the profession}

In the context of the theme, the sub-themes were identified as professional identityand professional culture. In the context of the sub-theme 'professional identity' the codes "self-respect, being honest, generous, proponent, objective, flexible, well-adjusted, virtuous, patient, trustworthy, consistent, determinant, cheerful, respectful, responsible and open to innovation" were identified. Related to the sub-theme 'professional culture' the codes "every aspect of the profession (behaviour, style, language, standpoint and way of thinking), consistency between the personality and profession, learning about other cultures, the occurrence of professional identity through implementation, an obstacle for change, acceptance of differences, common language, integration to the society, competencies pertain to the culture and having ethical principles". The students said that;

A professionalized nurse should be cheerful. Acceptance of the fact that the patient has anxiety also reflects the empathy and respect of the nurse towards the patient. (S13).

A nurse who is in the professional socialization process should have self-confidence. He/ she should have the necessary skills and knowledge. Being bumane has an important role as well. Because patients might experience anxieties. So, a nurse should approach the patients with self-confidence, eliminate the patient's anxiety, and try to help patients. (S14).

The student, pointed out to the importance, and stated that "A nurse should be consistent, what he/ she says and does should be consistent". (S2)

I think a nurse should be flexible... As we said, I think being able to adapt to every environment is very important at this point. (S4)

Not burting the patient... Being patient with the patient... And also a nurse should be neutral and objective towards the patients. (S5)

Regarding the sub-theme 'professional culture' and the codes, students shared their opinions. The students said that;

I think, professional culture refers to every aspect of the profession. I think it even includes behaviours, style, body language, standpoint, attitudes, and way of thinking. (S4).

We should provide service considering the cultural values of a society (S8).

It is a professional culture, so we become more objective. Rather than having cultural conflicts with others were interact, I think we should have a reconciling attitude (S15).

I think we are professionals, in this regard, when we set aside our culture and respect the culture of others (S7).

When a culture forms, the change is usually difficult... It felt like an obstacle to the change to me... When a culture forms, it settles. If I continue to proceed in that pattern, it will be difficult for me to change, too... That's what traditionalism is...(S4).

It was emphasized that the concepts of culture and professionalization are intertwined. It was emphasized that especially a professional individual should be aware of the culture of the society in which he lives. 
Öner, H., Denat, Y., \& Koruklu, N. (2021). The perceptions of university students' professional socialization process. Journal of Human Sciences, 18(4), 550-563. doi:10.14687/jhs.v18i4.6170

\section{Discussion}

Professional socialization is the process of gaining necessary knowledge, values, behaviours, attitudes and professional roles in the education and training processes (Shinyashiki et al., 2006; Browne et al., 2018; Sadeghi et al., 2019). In the literature, the concept of professional socialization was addressed mostly in the field of nursing education (Shahidi et al., 2014; Browne et al., 2018; Strouse et al., 2016), yet in recent years, research has been also focused on different professional education processes (Mazerolle et al., 2015; Flory, 2016; Everitt and Tefft, 2018). Professional socialization is a process of learning and adopting a new role that each student who is involved in professional training experiences (Thrasher et al., 2015; Jong et al., 2017). This study discussed the perceptions of a group of students who were studying at different departments on the professional socialization process, the emerging theme, sub-themes and codes based on the literature.

\section{Theme 1: Social adaptation}

The opinions of the students were analysed in the context of the question "bow do you perceive the concept of professional socialization?". The findings showed that professional socialization was perceived as a social adaptation process. Understanding the concept of socialization has key importance to manage the professional socialization process better and determine the educational strategies (Mazerolle et al. 2015; Langrehr et al., 2017; Tahmasbi et al., 2017). Professional socialization consists of two dimensions: primary and secondary (Corrêa Junior et al., 2017; Tahmasbi et al., 2017). The primary socialization refers to the period of family and school, and the secondary socialization refers to the university period (Corrêa Junıor et al., 2017). Professional socialization is a process of adaptation to social life and society, and it is a lifelong process (Corrêa Junior et al., 2017; Everitt and Tefft, 2018). The students who were studying at three different departments used particular expressions such as "adaptation to society", and "benevolence". Both in the primary and secondary socialization processes, the individual learns how to adapt to society. This adaptation occurs when the individual obtains a new role as a result of the educational process and becomes a part of a particular social group (Mazerolle et al., 2015; Freund et al., 2017; Everitt and Tefft, 2018). Individuals who obtain a professional role internalize the new realities and skills and also become a part of a new culture that has certain expectations regarding the values and standards (Thrasher et al., 2015; Jong et al., 2017; Everitt and Tefft, 2018). In this process, the culture of the universities has an important impact on the socialization of the students (Shinyashiki et al., 2006; Langrehr et al., 2017). As a result of the interviews conducted with the students on the definition of professional socialization, the concept of "social benevolence" was emerged in the context of a new role and process of social adaptation. The findings showed that the students used concepts such as social benevolence, socialization, social adaptation, meeting the expectations of society, and showing respect to rights and privacy. Similarly, the study conducted by Balci et al. (2019), which aimed to reveal the professional and organizational socialization experiences of primary school teachers, showed that the expectations of participants included being beneficial to their environment and society. In this context, it can be argued that the highlight of providing social service and benefits aspects of socialization is an important indicator in terms of professional socialization.

\section{Theme 2: Professional role achievement}

In the context of the theme, three sub-themes were identified: technical achievements, emotional achievements, and cognitive achievements. The themes and sub-themes were created based on the answers of the students given to the question "What technical competences, professional values, and attitudes should individuals (who are involved in the process) with professional socialization have?". An educational process aims to teach students professional knowledge, skills, and values (Thrasher et al., 2015; Tahmasbi et al., 2017; Everitt and Tefft, 2018). In line with the literature, the students expressed professional role achievements through technical, emotional, and cognitive dimensions. 
Öner, H., Denat, Y., \& Koruklu, N. (2021). The perceptions of university students' professional socialization process. Journal of Human Sciences, 18(4), 550-563. doi:10.14687/jhs.v18i4.6170

The students defined technical competencies with codes such as "communication skills, organization, observation, being competent, fulfilling the role, and standard applications". Students are required to gain certain competences to reach a professional status (Jong et al., 2017; Cerit and Temelli, 2018). Based on these competencies, a professional identity develops. A professional identity is closely linked to professional roles (Shahidi et al., 2014). However, it is a difficult process. Furthermore, in this process, the students' conscious preference for their future profession has a positive impact on gaining professional competencies (Shinyashiki et al., 2006; MacArthur et al., 2016). A study that analysed the professional socialization process of nursing students in Iran found out that students expected to learn communication skills (Dinmohammadi et al., 2017). The study also revealed, independently from the field of application, technical achievements such as communication skills can be obtained by taking an active role in patient care and working as a clinical nurse, and in this way establishing an intensive communication and interaction with the staff (Dinmohammadi et al., 2017). The students highlighted the role of standard application in the context of the sub-theme technical achievements. Similarly, Shahidi, et al (2014) revealed that professional identities of nursing students developed on the basis of professional applications. Giving an opportunity for students to benefit from mentorship services provided by experienced and competent educators might also make important contributions to the professionalization process (Thrasher et al., 2015; Salisu, et al., 2019;).

The success and positive feelings that students experience in the course of education could help them to increase their motivation. Similar to the literature, in this study, the students mentioned the concepts "motivation, emotional awareness, control of emotions, psychological resilience, sense of belonging, affection, and job satisfaction". Professional belonging develops in line with the experiences and effective role models in the education process (Freund et al., 2017). These concepts are important components of professional identity.

In the study, the students indicated the importance of cognitive achievements such as "problem-solving, knowing rights, being open/ready for innovation, being focused, respecting limits, sense of responsibility, following scientific knowledge, being investigative, and having sufficient professional knowledge" in the context of a professional role. In this sense, the knowledge and theoretical dimension of the professional identity are significant. In line with these findings, Balci et al (2019) stressed that teachers required training programs and seminars to adapt to school life. Having quality and significant learning experiences widens the perception of students and helps them to learn new concepts more conveniently (MacArthur et al., 2016; McGregor and Nova Scotia, 2019). Particularly in nursing education, teaching communication skills, and ethical principles to students is possible only with an educational process which is integrated with clinical applications (Jong et al. 2017; Tahmasbi et al., 2017; Salisu, et al., 2019). A research study which examined the perceptions of medical school students on the role of being a medical doctor indicated that the quality of experiences gained during the application environments had an important role in terms of the perception of identity, and medical school students started to feel the role of being a medical doctor with the growing self-confidence that stemmed from the communication and relationships that they established with patients (Pitkala and Mantyranta, 2003). The student should take certain responsibilities regarding the professional application fields to develop perceptions of a professional role, in line with the professional limits and learning objectives (Mac Arthur et al., 2016). It is believed that responsibilities have great importance in terms of the professional role achievement of a student.

\section{Theme 3: Adoption of the profession}

Thetheme was created based on the answers given to the question "What is a professional culture? What the concept of professional culture cover? Do you think the profession should have a culture? What do you understand from the concept of 'professional culture?". Regarding the theme, the sub-themes were identified as professional identity and professional culture. The literature indicated that distinctive professional roles which have limits led to a positive professional identity development (Shahidi et 
Öner, H., Denat, Y., \& Koruklu, N. (2021). The perceptions of university students' professional socialization process. Journal of Human Sciences, 18(4), 550-563. doi:10.14687/jhs.v18i4.6170

al., 2014; Thrasher et al., 2015). In the context of the sub-theme professional identity, the codes "self-respect, being honest, generous, proponent, objective, flexible, well-adjusted, virtuous, patient, trustworthy, consistent, cheerful, respectful, responsible and open to innovation" were identified. Professional identity continues in the course of education, and also afterwards, and occurs on the basis of experiences (Thrasher et al., 2015; Mac Arthur et al., 2016; Romar and Frisk, 2017). At the beginning of the educational process, students' level of awareness and consciousness on the profession was found relatively lower, yet it increased gradually in the following years of education and students experienced self-awareness, and personal and professional integration (Mazerolle et al., 2015; Dinmohammadi et al., 2017). In this process, establishing positive communication and cooperation made significant contributions to students' professional development (Corrêa Junior et al., 2017).

In the context of the sub-theme professional culture, the students made definitions that included components related to the profession such as opinion, behaviour, style, and language. Along with it, the students explained professional culture through the concepts including consistency between the profession and personality, learning about different cultures, the occurrence of professional identity through implementation, an obstacle for change, acceptance of differences, common language, integration to the society, competencies pertain to the culture and having ethical principles. The concept of professional socialization emphasizes how individuals learn a profession within the culture of that profession (Flory, 2016; Strouse et al., 2016). Everitt and Tefft (2018) remarked that prospective teachers' needs for adaptation and professional culture could emerge only in the context of applications/experiences. In the study of Flory (2016), the students of physical education and sports teaching emphasized that a teacher should have certain competencies to provide education to students with different cultural backgrounds. Similarly, all of the students who participated in this study also expressed the importance of having appropriate attitudes to the culture of the society along with learning professional culture in the professional socialization process. In a study that investigated the components which formed professional socialization of physical education and sports teachers, one teaching assistant highlighted the challenges that teachers faced regarding discipline-related issues and socio-cultural aspects (Corrêa Junior et al,. 2017). Almost all of the students were aware of the role of the culture and values in the context of performing a profession, and this might also indicate that the students internalized these concepts through the professional socialization process (Mazerolle et al., 2015; Tahmasbi et al., 2017; Schmidt and McArthur, 2018). Furthermore, students become professionals within the socialization process by learning the implicit culture of the profession, its application, and values (Strouse et al., 2016; Salisu et al., 2019; Tahmasbi et al., 2017). One of the main objectives of professional socialization is to enable students to internalize professional culture as a way of life.

\section{Conclusions}

This study was conducted to identify the perceptions of students, who were studying at two different departments, on the process of professional socialization. As a result of the two focus group interviews, three themes were created. The students' perceptions of professional socialization were defined through the themes: social adaptation, professional role achievements, and adaptation of the profession. The results of the study revealed that the university students' perceptions were found comprehensive. The results also showed that the students could assess this process in a multidimensional way, and they were in the process of internalizing the identity of the profession that they were trained to perform.

In line with the results of the study, it is believed that understanding how the professional socialization process is perceived and understood from the perspective of educators could make a great contribution to the professional socialization process of the students. It is suggested to identify the process experienced by students who were studying at two different departments and have different grade-levels, to review the study program in line with these opinions, and to re-adjust the study program to contribute to the professional socialization process of students. 
Öner, H., Denat, Y., \& Koruklu, N. (2021). The perceptions of university students' professional socialization process. Journal of Human Sciences, 18(4), 550-563. doi:10.14687/jhs.v18i4.6170

\section{Limitations}

The results of this qualitative study were limited to the perceptions of a group of students, who were studying at two different faculties and three different departments, on the process of professional socialization. In the study, two focus group interviews were conducted with the students who were studying at two different faculties and three different departments. The strength of the study could be enhanced by increasing the number of focus groups.

\section{References}

Balc1, A., Karabulut, N., Gürses Kürçe, S., \& Ernas, S. (2019). Teachers’ organizational and professional socialization: The case of Ankara". Journal of Education and Instruction, 9(1): 305350, doi:10.14527/pegegog.2019.010.

Büyüköztürk, Ş. Çakmak, K.E. Akgün, E.Ö., Karadeniz, Ş., \& Demirel, F. (2014). Scientific Research Methods. Ankara: Pegem Academy. (Original Work Published in Turkish)

Browne, C., Wall, P., Batt, S., \& Bennett, R. (2018). Understanding perceptions of nursing professional identity in students entering an Australian undergraduate nursing degree. Nurse Education in Practice, 32: 90-96. doi:10.1016/i.nepr.2018.07.006

Cerit, B., \& Temelli, G. (2018). Examination of professional behaviors according to the gender and grade level in nursing students. Journal of Health and Nursing Management, 5(3): 164-171. doi:10.5222/SHYD.2018.164 (Original Work Published in Turkish)

Cohen, H. (1981). The nurses quest for professional identity. Menlo Park: CA, Addison\&Wesley Publishing Company.

Corrêa Junıor, J., Souza Neto, S., \& Vedovatto Iza, D.F. (2017). Supervised curricular internship: locus of professional socialization, habitus and production of knowledge. Rev Bras Educ Fis Esporte, (São Paulo) Jan-Mar;31(1): 153-169.doi:10.11606/1807-5509201700010153

Creswell, J.W. (2016). Qualitative research and research design according to five approaches. Translation editors: M. Bütün and S.B. Demir, Political Bookstore, Ankara.

Dinmohammadi, M.R., Peyrovi, H., \& Mehrdad, N. (2017). Professional socialization of Iranian BSN students: a grounded theory study. Journal of Caring Sciences, 6(4): 359-369. doi:10.15171/jcs.2017.034

Edmunds, H. (2000). The focus group research handbook. McGraw-Hill, New York.

Everitt, J. G., \& Tefft, T. (2018). Professional socialization as embedded elaborations: Experience, institutions, and professional culture throughout teacher careers. Symbolic Interaction, 42(4): 564-587. doi:10.1002/SYMB.409

Freund, A., Cohen, A., Blit-Cohen E., \& Dehan, N. (2017). Professional socialization and commitment to the profession in social work students: A longitudinal study exploring the effect of attitudes, perception of the profession, teaching, training, and supervision. Journal of Social Work, 17(6): 635-658. doi:10.1177/146801731665199

Flory, S.B. (2016). Professional socialization experiences of early career urban physical educators. European Physical Education Review, 22(4): 430-449. doi:10.1177/1356336X15616074

Hesse-Biber, S., \& Leavy, P. (2006). The practice of qualitative research. Sage Publications, California.

Jong, E.I.F-de, Kool L., Peters, L.L., \& Jansen, D.E.M.C. (2017). Perceptions of nearly graduated fourth year midwifery students regarding a 'good midwife' in the Netherlands. Midwifery, 50, July:157-162. doi:10.1016/j.midw.2017.04.008

Ke, Y.T., Kuo, C-C., \& Chich-Hsiu, H. (2017). The effects of nursing preceptorship on new nurses' competence, professional socialization, job satisfaction and retention: A systematic review. J Adv Nurs, 73: 2296-2305. doi:10.1111/jan.13317 
Öner, H., Denat, Y., \& Koruklu, N. (2021). The perceptions of university students' professional socialization process. Journal of Human Sciences, 18(4), 550-563. doi:10.14687/jhs.v18i4.6170

Langrehr, K.J., Green, C.E., \& Lantz, M. (2017). The implications of doctoral students' professional socialization experiences in graduate training. The Counseling Psychologist, 45(8): 1162-1183. doi:10.1177/0011000017748588

Light, D. (1979). Uncertainty and control in professional training. Journal of Health and Social Behavior, 20(4): 310-322.

Limoges, J., \& Jagos, K. (2015). The influences of nursing education on the socialization and professional working relationships of Canadian practical and degree nursing students: A critical analysis. Nurse Education Today, 35(10), October: 1023-1027. doi:10.1016/j.nedt.2015.07.018

Lurie, E. E. (1981). Nurse practitioners: Issues in professional socialization. Journal of Health and Social Behavior, 22, March: 31-48.

Lum, J.L.J. (1988). Reference groups and professional socialization. In M.E. Hardy \& M.E. Conway(Eds.), Role theory perspective for health professionals(Second Edition). (ss.257-272). America: Hall

MacArthur B.L., Dailey S.L., Villagran M.M. (2016). Understanding healthcare providers' professional identification: the role of interprofessional communication in the vocational socialization of physicians. Journal of Interprofessional Education \& Practice, 5 December: 11-17. doi:10.1016/j.xjep.2016.09.001

Mazerolle, S. M., Eason, C. M., Clines, S., \& Pitney, W. A. (2015). The professional socialization of the graduate assistant athletic trainer. Journal of Atbletic Training, 50(5): 532-541. doi:10.4085/1062-6050-50.1.03

McGregor, S. L. T., \& Nova Scotia, S. (2019). Conceptual change during the professional socialization process. Journal of Family and Consumer Sciences Education, 36 (1): 21-33.

Merton, RK. (1969). Student-physician: Introductory. Cambridge: Harvard University Press.

Miles, M. B., \& Huberman, A.M. (1994). Qualitative data analysis: An expanded source book. California: Sage.

Neto, S.de S., Iza, D.F.V., \& Silva, M.F.G. (2017). Learning of teaching in the professional socialization in physical education. Motriz, Rio Claro, 23(2): 1-10. doi:10.1590/S19806574201700020008

Ousey, K. (2009). Socialization of student nurses - the role of the mentor. Learning in Health and Social Care, 8(3):175-184.doi:10.1111/j.1473-6861.2008.00209.x

Perez, R. J. (2016). A conceptual model of professional socialization within student affairs graduate preparation programs. Journal for the Study of Postsecondary and Tertiary Education, 1: 35-52

Pitkala, K.H., \& Mantyranta, T. (2003). Professional socialization revised: medical students' own conceptions related to adoption of the future physician's role--a qualitative study. Medical Teacher, 25(2): 155-160. doi:10.1080/0142159031000092544

Romar, J. E., \& Frisk, A. (2017). The influence of occupational socialization on novice teachers' practical knowledge, confidence and teaching in physical education. Qualitative Research in Education, 6(1): 86-116. doi:10.17583/qre.2017.2222

Sadeghi Avval Shahr, H., Yazdani, S., \& Afshar, L. (2019). Professional socialization: An analytical definition. J Med Ethics Hist Med. 12, 17: 1-14.

Salisu, W. J., Nayeri, N. D., Yakubu, I., \& Ebrahimpour, F. (2019). Challenges and facilitators of professional socialization: a systematic review. Nursing Open, 6:1289-1298. doi:10.1002/nop2.341.

Sancak Aydin, G., Çilsalar Sagnak, H. (2020). How do pre-service teachers feel? examination of their emotions and experiences in the scope of teaching practice. Eurasian Journal of Researches in Social and Economics (EJRSE), 7(9): 85-100. (Original Work Published in Turkish)

Schmidt, B.J., \& McArthur, E.C. (2018). Professional nursing values: A concept analysis. Nurs Forum, 53:69-75.doi:10.1111/nuf.12211 
Öner, H., Denat, Y., \& Koruklu, N. (2021). The perceptions of university students' professional socialization process. Journal of Human Sciences, 18(4), 550-563. doi:10.14687/jhs.v18i4.6170

Shahidi, L.H., Vahidi, M., Mahram, B., Areshtanab, H.N., \& Zarghi, N. (2014). Professional identity development in nursing students: Eisner's Evaluation Model. Res Dev Med Educ, 3(1): 3743. doi:10.5681/rdme.2014.009

Shuval, J. T. \& Adler, I. (1980). The role of models in professional socialization. Social Science \& Medicine, Part A: Medical Psychology \& Medical Sociology 14(1), 1-88.

Shinyashiki, G. T., Costa Mendes, I.A. M., Trevizan, A., \& Day, R.A. (2006). Professional socialization: Students becoming nurses. Rev Latino-am Enfermagem julho-agosto; 14(4):6017601.

Strouse, S.M., \& Nickerson, C.J. (2016). Professional culture brokers: Nursing faculty perceptions of nursing culture and their role in student formation. Nurse Education in Practice, 18: 10-15. doi:10.1016/j.nepr.2016.02.008

Tahmasbi, S., Mirzaiean, S., Bonyadi, M., \& Mohammadi, P. (2017). Iranian nurses professional socialization. Journal of Client-Centered Nursing Care, 3(4): 283-290. doi:10.32598/jccnc.3.4.283

Thrasher A.B., Walker S.E., Hankemeier D.A, Pitney W.A. (2015). Supervising athletic trainers' perceptions of professional socialization of graduate assistant athletic trainers in the collegiate setting. Journal of Athletic Training, 50(3): 321-333. doi: 10.4085/1062-6050-49.3.67

Yazdannik, A., Yousefy, A., \& Mohammad, S. (2017). Exploring the dominant discourse of baccalaureate nursing education in Iran. Iranian Journal of Nursing and Midwifery Research, 22 (1), January-February: 19-25.

Yıldırım, A., \& Şimşek, H. (2008). Qualitative research methods in social sciences (6th Edition). Seçkin Publishing, Ankara.(Original Work Published in Turkish)

Zarshenas, L., Sharif, F., Molazem, Z., Khayyer, M., Zare, N., Ebadi A. (2014). Professional socialization in nursing: A qualitative content analysis. Iranian Journal of Nursing and Midwifery Research, July-August, 19(4); 432-438. 